\title{
Cisalpine translation
}

\author{
By Lev Osherovich, Senior Writer
}

In Italy, a scarcity of local venture capital and biotechs has left academic researchers with few opportunities to commercialize their discoveries. A new drug discovery center at the Italian Institute of Technology hopes to change that by stepping into the preclinical development space and occupying a role in the value chain traditionally held by venture-backed startups.

Only two Italian biotechs-autoimmune, inflammation and dermatology company Creabilis Therapeutics S.p.A. and cancer company EOS S.p.A.- - have disclosed seed or series A rounds since 2008 .

Thus, the Italian Institute of Technology (IIT) has created the Drug Discovery and Development at the Italian Institute of Technology (D3) center as the main focus of an effort to jump-start scientific entrepreneurship in Italy.

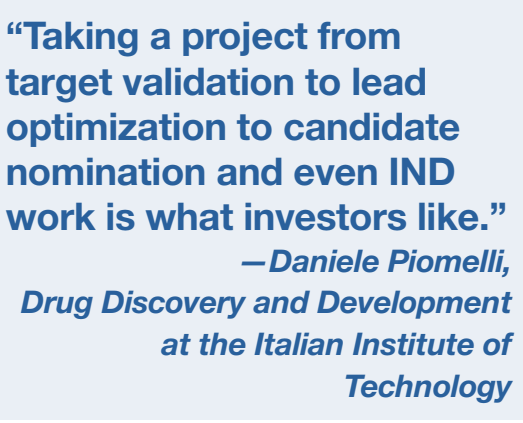

disease $(\mathrm{AD})$ targets: $\beta$-site APP-cleaving enzyme 1 (BACE1) and glycogen synthase kinase $3 \beta$ (GSK3B).

\section{A case for collaboration}

The challenge now is for researchers, investors and pharmas to cooperate early on to make sure D3's projects have a commercial future.

The institute hopes to collaborate with industry on target selection and lead compound discovery to generate jointly held IP. This scenario requires that the collaborators spell out who pays for what and how credit is apportioned, said J. Desmond Fitzgerald, a director of the consulting firm BioConsulting Ltd.

"You have to take very careful steps early on so that there are no assumptions," said Fitzgerald. Because career advancement in academia is based on publications and IP, determining whose names will be on papers published by the collaboration should take place "at the first or second discussion," not as an afterthought once the work is done, he said.

On the flip side, Fitzgerald said industry collaborators will expect clear milestones and willingness on the part of academics to change direction if current approaches aren't working.

Peppi Prasit, CSO of small molecule company Amira Pharmaceuticals Inc., said that early collaboration on target selection is essential.

To get companies interested in working with D3 researchers, "they have to choose the right
Piomelli, the center will use public funds to take academic biomedical discoveries from in vitro and in vivo proof of principle through preclinical development.

Upon completion of preclinical development of individual projects, D3 hopes to spin out companies and attract investors.

"D3 tries to bridge the gap between academic and industry work," said Piomelli, who also is a professor of pharmacology at the University of California, Irvine. "Taking a project from target validation to lead optimization to candidate nomination and even IND work is what investors like."

D3's staff is organized more like a biotech than a traditional academic institution. Instead of having independent principal investigators with postdocs and students, D3 is hiring about 75 researchers to work in teams on various aspects of drug discovery and development. These include biophysics, computational chemistry, medicinal chemistry, structure determination and pharmacology.

D3's infrastructure and equipment cost $€ 14.4$ million (\$20 million) to build, and the program has an annual $€ 5$ million ( $\$ 6.8$ million) budget from the IIT, which is funded by the Italian Ministry of the Treasury and the Ministry of Universities and Research. Piomelli said that D3 plans to raise additional money from grants and partnering agreements.

The initial focus will be on pain, inflammation and neurodegenerative diseases. For example, D3 is now screening for selective inhibitors of fatty acid amide hydrolase (FAAH), which is a pain target, and $\mathrm{N}$-acylsphingosine amidohydrolase-like (ASAHL; NAAA), an inflammation target. ${ }^{1}$ Piomelli's team is also working on a dual inhibitor of two Alzheimer's target," said Prasit. "It has to be a hot target with animal validation. We choose targets that haven't yet broken out and will be something big in a few years."

Andrew Dray, chief scientist at AstraZeneca plc'sMontreal research center, said that talking to pharmas beforehand about target selection and drug design strategy would ensure that there's commercial interest in the resulting product.

Giovina Ruberti, head of research at the Institute of Cell Biology at the National Research Council of Italy, also made a case for coordinating D3's drug development program with clinicians and regulators. Ruberti is the Italian representative for the Innovative Medicines Initiative, an EU-wide nonprofit institution that hopes to coordinate regulatory policy to accelerate drug development.

Speaking at the D3 kickoff symposium last week, William Burns, the recently retired CEO of Roche's Roche Pharma unit, said that the safetyoriented regulatory landscape has changed the game for target selection. "Any innovation toward which we aspire needs to move the needle of medicine," he said, because the added cost and complexity of demonstrating safety has reduced the profitability of medicines that offer only modest benefits over the current standard of care.

Ed Saltzman, president of the business development consultancy Defined Health, thinks the time is ripe for entities such as D3. He thinks pharma's patent cliff will severely curtail spending on early $R \& D$, citing recent $R \& D$ and Phase I contractions at AstraZeneca, Pfizer Inc. and GlaxoSmithKline plc. 


\section{ANALYSIS}

According to Saltzman, the industry consensus is shifting toward the view that academia is better than industry at discovery research.

"The idea that we can industrialize a crazy and creative process has been a significant miscalculation," he said.

Osherovich, L. SciBX 3(15); doi:10.1038/scibx.2010.455

Published online April 15, 2010

REFERENCES

1. Solorzano, C. et al. Proc. Natl. Acad. Sci. USA 106, 20966-20971 (2009)

COMPANIES AND INSTITUTIONS MENTIONED

Amira Pharmaceuticals Inc., San Diego, Calif.
AstraZeneca plc (LSE:AZN; NYSE:AZN), London, U.K. BioConsulting Ltd., Bristol, U.K.

Creabilis Therapeutics S.p.A., Colleretto Giacosa, Italy Defined Health, Florham Park, N.J.

Drug Discovery and Development at the Italian Institute of Technology, Genoa, Italy

EOS S.p.A., Milan, Italy

GlaxoSmithKline plc (LSE:GSK; NYSE:GSK), London, U.K.

Innovative Medicines Initiative, Brussels, Belgium

Italian Institute of Technology, Genoa, Italy

National Research Council, Milan, Italy

Pfizer Inc. (NYSE:PFE), New York, N.Y.

Roche (SIX:ROG; OTCQX:RHHBY), Basel, Switzerland

University of California, Irvine, Calif. 